\title{
Lithium Toxicity From an Internet Dietary Supplement
}

\author{
DK Pauzé, MDa, DE Brooks, $M D^{a b}$ \\ aDepartment of Emergency Medicine, University of Pittsburgh Medical Center, Pittsburgh, PA \\ bDivision of Medical Toxicology, University of Pittsburgh Medical Center, Pittsburgh, PA
}

\begin{abstract}
Introduction: The widespread availability of medications and herbal products on the Internet has increased the potential for poisonings. We are reporting a case of mild, acute lithium toxicity occurring after the intentional misuse of a lithium-containing "dietary supplement" (Find Serenity Now®) obtained over the Internet.

Case Report: An 18-year-old woman presented to our emergency department (ED) after ingesting 18 tablets of Find Serenity Now ${ }^{\circledR}$; each tablet contained, according to the listing, $120 \mathrm{mg}$ of lithium orotate [3.83 mg of elemental lithium per $100 \mathrm{mg}$ of (organic) lithium orotate compared to $18.8 \mathrm{mg}$ of elemental lithium per $100 \mathrm{mg}$ of (inorganic) lithium carbonate]. The patient complained of nausea and reported one episode of emesis. Her examination revealed normal vital signs. The only finding was a mild tremor without rigidity. Almost 90 minutes after the ingestion, her serum lithium level was $0.31 \mathrm{mEq} / \mathrm{L}$, a urine drug screen was negative, and an electrocardiogram (ECG) showed a normal sinus rhythm. The patient received intravenous fluids and an anti-emetic; one hour later, her repeat serum lithium level was $0.40 \mathrm{mEq} / \mathrm{L}$. After 3 hours of observation, nausea and tremor were resolved, and she was subsequently transferred to a psychiatric hospital for further care. Prior human and animal data have shown similar pharmacokinetics and shared clinical effects of these lithium salts.
\end{abstract}

Discussion: Over-the-Internet dietary supplements may contain ingredients capable of causing toxicity in overdose. Chronic lithium toxicity from ingestion of this product is also of theoretical concern.

\section{INTRODUCTION}

The proliferation of the Internet has allowed a large increase in online medications and herbal remedies $[1,2]$. These substances are advertised without regulation, and they are purchased and used without supervision or monitoring. The widespread availability of herbal and medicinal products from Internet sources has increased the potential for poisonings. Patients who obtain these products are subject to toxicity, drug-drug interactions, and other adverse effects. We are reporting a case of mild, acute lithium toxicity that occurred after the intentional misuse of a lithium-containing "dietary supplement" (Find Serenity Now®) obtained over the Internet.

\section{CASE REPORT}

An 18-year-old woman presented to our ED after an intentional ingestion of 18 tablets of Find Serenity Now®. (The product's supplemental facts listed each tablet as containing $120 \mathrm{mg}$ of lithium orotate). The patient initially complained of nausea and reported one episode of emesis shortly after the ingestion. Physical examination revealed normal vital signs. The only finding was mild, diffuse tremor without rigidity. Almost 90 minutes after the ingestion, her serum lithium level was $0.31 \mathrm{mEq} / \mathrm{L}$. A comprehensive urine drug screen using gas chromatography and mass spectroscopy was negative and an ECG showed a normal sinus rhythm. The patient received intravenous fluids and

Keywords: Internet, lithium, toxicity

Notes: Case presented at the North American Congress of Clinical Toxicology, Orlando, FL, September 2005. No outside funding of any kind was used for this study.

Corresponding Author: Daniel Pauzé 230 McKee Place, Suite 500, Pittsburgh, PA 15213. Email: pauzedk@upmc.edu 
an anti-emetic. One hour later the repeat serum lithium level was $0.40 \mathrm{mEq} / \mathrm{L}$. After 3 hours of observation (4.5 hours post ingestion), her nausea and tremor had resolved, she tolerated oral fluids, and she had no ataxia. She was subsequently transferred to a psychiatric hospital for further evaluation and care.

\section{DISCUSSION}

Find Serenity Now ${ }^{\circledR}$ (Urban Nutrition, LLC) is advertised as "the all-natural, mineral form of Lithium." It is reported as "effective, safe, non-toxic, non-addictive, and has no side effects" [3]. It is readily available over the Internet. Each tablet is listed as containing $120 \mathrm{mg}$ of lithium orotate (3.83 $\mathrm{mg}$ of elemental lithium per $100 \mathrm{mg}$ of [organic] lithium orotate compared to $18.8 \mathrm{mg}$ of elemental lithium per $100 \mathrm{mg}$ of [inorganic] lithium carbonate). Animal models suggest that lithium orotate has similar kinetics, but the lithium orotate may achieve higher tissue concentrations at the same dosages commonly prescribed for lithium carbonate and lithium citrate formulations [4-6]. This may be secondary to lower renal clearance of the lithium orotate salt $[5,6]$.

Lithium's widespread use and its narrow therapeutic index can lead to adverse effects in up to $90 \%$ of all users [7-11]. Most toxicity is mild and includes lethargy, vomiting, ataxia, and myoclonus, but massive, acute ingestions or severe chronic toxicity can lead to coma or seizures. Other adverse effects include thyroid and parathyroid abnormalities, serotonergic crisis, cardiovascular abnormalities, and nephrogenic diabetes insipidus [9,11-13]. Onset and severity of symptoms vary upon the timing of ingestion and product formulation. The risk of toxicity increases with increased age, renal insufficiency, hyponatremia, volume depletion, drug-drug interactions, and comorbidities or co-ingestions $[14,15]$. Significant toxicity tends to occur when levels are well above the upper therapeutic level $(1.5 \mathrm{mEq} / \mathrm{L})$; however, lithium's variable absorption and delayed tissue concentrations make interpretation of serum levels difficult. Toxicity may also occur at lower levels, especially in the setting of chronic use $[7,8,11,16]$.

Over-the-Internet dietary supplements and medications are becoming increasingly common [1]. Little data exists detailing the true extent and availability of these substances, but several Internet sites exist for their appropriation. These products are immune from extensive scrutiny and regulation and several product-sites fail to adequately describe product formulations, potential adverse effects, or contraindications to their product $[1,17]$. A study by Ashar et al. showed that $41 \%$ of internet sites marketing ephedra did not contain information about potential contraindications or adverse effects, a surprisingly high number considering the potential dangers of the product [18].

This report illustrates that over-the-Internet supplements are capable of causing adverse clinical effects following an acute exposure. It is plausible that significant toxicity may develop after a massive overdose or from chronic ingestion. Drug-drug interactions and other adverse effects are also of concern. Physicians must be aware of the increasing use of non-prescribed herbal and supplemental medications and their possible toxicity profiles and interactions.

The authors have no potential financial conflicts of interest to report.

\section{REFERENCES}

1. Morris C, Avorn J Internet marketing of herbal products. JAMA 2003;290(11):1505-1509.

2. Henney J. Cyperpharmacies and the role of the US Food and Drug Administration. J of Med Internet Research

2001;3(1):E3.

3. Find Serenity Now Home Page. Urban Nutrition, LLC. Accessed January 30, 2007. http://www.findserenitynow.com.

4. Smith DF. Lithium orotate, carbonate and chloride: pharmacokinetics, polyuria in rats. Br J Pharmacol. 1976;56(4):399-402.

5. Smith DF, Schou M. Kidney function and lithium concentrations of rats given an injection of lithium orotate or lithium carbonate. J Pharm Pharmacol. 1979;31(3):61-63.

6. Kling MA, Manowitz P, Pollack IW. Rat brain and serum lithium concentrations after acute injections of lithium carbonate and orotate. J Pharm Pharmacol. 1978;30(6):368-370.

7. Timmer RT, Sands JM. Lithium intoxication. J Am Soc Nephrol. 1999;10:666-674.

8. Sadosty AT, Groleau GA, Atcherson MM. The use of lithium levels in the emergency department. J of Emergency Med. 1999; 17(5):887-891.

9. Gill, J, Singh H, Nugent K. Acute lithium intoxication and neuroleptic malignant syndrome. Pharmacotherapy

2003;23(6):811-815.

10. Chen KP, Shen W, Lu ML. Implication of serum concentration monitoring in patients with lithium intoxication. Psychiatry and Clinical Neurosciences.

2004; $58: 25-29$.

11. Groleau G. Lithium toxicity. Emerg Med Clinics of North America. 1994;12(2): 511-528.

12. Kores B, Lader MH. Irreversible lithium neurotoxicity: an overview. Clin Neuropharmacol. 1997;20:283-239.

13. Oakley P, Whyte I, Carter G. Lithium toxicity: An iatrogenic problem in susceptible individuals. Australian and New Zealand J of Psychiatry. 2001;35:833.

14. Okusa MD, Crystal LJT. Clinical manifestations and management of acute lithium intoxication. American J of Med.

1994;97:383-388.

15. Simard M, Umbiner B, Lee A, Lewis H, Norman D. Lithium carbonate intoxication: A case report and review of the literature. Arch Intern Med. 1989;149:36-46.

16. Astruc B, Petit P, Abbar M. Overdose with sustainedrelease lithium preparations. EUR Psychiatry. 1999;14: 172-174.

17. Drazen J. Inappropriate advertising of dietary supplements. N Engl J Med. 2003;348(9)777-778.

18. Ashar, B, Miller R, Getz K, Picard C. A critical evaluation of Internet marketing of products that contain ephedra. Mayo Clinic Proceedings. Aug 2003;78(8):944-946.

19. O'Brien B, Quigg C, Leong T, Severe cyanide toxicity from vitamin supplements. Eur J of Emerg Med Oct

2005;12(5):257-258. 